\title{
Implementation of Intentional Touch for Geriatric Patients with Chronic Pain: A Qualitative Pilot Study
}

\author{
Barbara Stöckigt $^{\mathrm{a}}$ Ralf Suhr ${ }^{\mathrm{b}}$ Daniela Sulmann ${ }^{\mathrm{b}}$ Michael Teut ${ }^{\mathrm{a}}$ \\ Benno Brinkhaus $^{\mathrm{a}}$ \\ anstitute for Social Medicine, Epidemiology and Health Economics, Charité - Universitätsmedizin Berlin, Berlin,

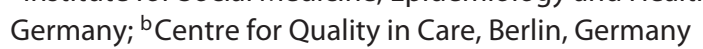

\section{Keywords}

Qualitative research · Touch - Chronic pain · Intention ·

Geriatric nursing · Professional-patient relation •

Relaxation · Well-being

\section{Summary \\ Background: Intentional Touch (InTouch) refers to a soft physical touch with the aim to ease complaints and enhance well-being. Central questions were perception of InTouch by nurses and patients and possible effects on pain perception. Patients and Methods: InTouch was developed by stake- holder involvement. Nurses working in geriatric care re- ceived expert training in InTouch. Semi-structured inter- views and participant observation (including video record- ing) were conducted with nurses applying and patients with chronic pain receiving InTouch after the beginning of the intervention and after 4 weeks. Interviews were analyzed based on Qualitative Content Analysis and video recordings based on Qualitative Visual Analysis. Results: Six elderly pa- tients with chronic pain and 6 nurses were included. Nurses and patients equally described relaxation, well-being, and a sensation of warmth during the intervention. Patients re- ported no pain during the intervention. After the interven-}

Michael Teut and Benno Brinkhaus contributed equally to this work. Trial registration: DRKS-ID: DRKS00013112.

\begin{tabular}{ll}
\hline KARGER & ( ) 2019 The Author(s) \\
& Published by S. Karger AG, Basel \\
E-Mail karger@karger.com & This article is licensed under the Creative Commons Attribution- \\
www.karger.com/cmr & NonCommercial-NoDerivatives 4.0 International License (CC BY- \\
& NC-ND) (http://www.karger.com/Services/OpenAccessLicense). \\
& Usage and distribution for commercial purposes as well as any dis- \\
tribution of modified material requires written permission.
\end{tabular}

tion, 3 patients each experienced pain relief or no change. Patients described better drive and positive feelings, and nurses felt empowered in their nursing work. Empathetic attention had special importance for improving the therapeutic relationship. Conclusion: The results of this study suggest that InTouch promoted relaxation, well-being, and pain relief for elderly people suffering from chronic pain and may contribute positively to the therapeutic relationship.

(c) 2019 The Author(s)

Published by S. Karger AG, Basel

\section{Intentionale Berührung für geriatrische Patienten mit chronischen Schmerzen: Eine qualitative Pilotstudie}

\section{Schlüsselwörter}

Qualitative Studie · Berührung · Chronische Schmerzen · Intention · Altenpflege · Therapeutische Beziehung • Entspannung $\cdot$ Wohlbefinden

\section{Zusammenfassung}

Hintergrund: Intentionale Berührung ist eine leichte körperliche Berührung mit dem Ziel Beschwerden zu reduzieren und Wohlbefinden zu verbessern. Primäre Fragestellungen waren das subjektive Erleben von Intentionaler Berührung und mögliche Auswirkungen auf 
die Schmerzwahrnehmung. Patienten und Methodik: Die Intervention Intentionale Berührung wurde durch Stakeholder-Involvement entwickelt. Danach wurden Pflegekräfte darin durch Experten geschult. Es wurden semistrukturierte Interviews und teilnehmende Beobachtungen (mit Videoaufnahmen) mit Pflegekräften, die Intentionale Berührung anwandten, und mit chronischen Schmerzpatienten, die Intentionale Berührung empfingen, zu Beginn der Intervention und nach 4 Wochen durchgeführt. Die Interviews wurden auf der Grundlage qualitativer Inhaltsanalyse und die Videoaufnahmen in Anlehnung an qualitative Bild- und Videointerpretation ausgewertet. Ergebnisse: Es wurden 6 Pflegekräfte und 6 chronische Schmerzpatienten eines Altenpflegeheims rekrutiert. Pflegekräfte und Patienten beschrieben gleichermaßen Entspannung, Wohlsein und Wärme während der Behandlung. Die Patienten verspürten Schmerzfreiheit während der Behandlungen; darüber hinaus erlebten jeweils 3 Patienten Schmerzlinderung oder keine Veränderung. Die Patienten beschrieben weiterhin verbesserten Antrieb und positive Gefühle und die Pflegekräfte Empowerment in Bezug auf ihre pflegerische Arbeit. Besondere Bedeutung hatte die empathische Zuwendung in der Beziehung zwischen Pflegekraft und Patient. Fazit: Die Ergebnisse der Studie weisen darauf hin, dass Intentionale Berührung Entspannung, Wohlsein und Schmerzlinderung bei chronischen Schmerzpatienten fördern und die therapeutische Beziehung verbessern könnte.

(c) 2019 The Author(s)

Published by S. Karger AG, Basel

\section{Background}

Physical touch is a basic part of medical treatment and care with important dimensions in medical examination, caregiving, and various forms of treatments. More broadly, physical touch has various symbolic meanings, e.g., politeness associated with social greeting or comfort $[1,2]$. Technological advances as well as economic constraints in health care have affected the very meaning of practitioner/ patient touch; in fact, patients report feeling disappointed by the absence or infrequency of physical touch [3].

In complementary and integrative medicine (CIM), physical touch therapy (e.g., therapeutic touch, healing touch, Reiki) is used to treat many conditions, including pain, stress, fear, depressive symptoms, and agitation, and, in general, to enhance well-being and relaxation. In surgery, physical touch therapy is used to enhance wound healing and perioperative nausea. Also, it is said to improve therapeutic relationships and communication [47]. However, the lack of high-quality studies has caused the efficacy and effectiveness of physical touch to remain anecdotal rather than clearly demonstrated [5].
In a broad social sense, physical touch has traditionally served as a religious or cultural signifier, depending on the intention and context in which it is used. Intention is a focused and purposeful thought. In nursing, for example, the intention can be set to be present, aware, and compassionate and aiming at relaxation, well-being, and healing. This might create a healing environment that fosters illness-coping strategies and improves self-awareness $[8,9]$.

In this study, the link between intention, physical touch, and their healing capacities was of primary interest. We chose to focus on chronic pain because of its prevalence among the elderly, which can be problematic to address in everyday nursing routines $[10,11]$. In a first step, the intervention was developed, which we named Intentional Touch (InTouch). Unlike therapeutic touch or massage, InTouch does not refer to a specific method, technique, or concept, but should refer simply to a soft physical touch with a positive intention to ease complaints and enhance well-being. In the qualitative part of the study, the subjective experience of nurses and elderly patients with chronic pain relative to InTouch was examined.

Our research questions were:

- How do nurses and patients perceive and experience InTouch?

- How do nurses and patients describe their therapeutic experiences concerning changes in pain perception, in case there is any?

\section{Methods}

The project was structured into 2 parts.

Part 1: Development of the Study Intervention of InTouch in Geriatric Care

InTouch was developed by stakeholder involvement with nurses, patients, scientists, and experts in different therapies working with physical touch. Major points of discussion were the intention (e.g., calming, pain reduction), the duration (rather short, easy to integrate in everyday nursing life), type of touch (e.g., soft, whole hand, or fingertips), and location (e.g., at pain loci or distant from them). The research team developed the therapeutic concept taking into account stakeholder consent. Then, nurses in elderly care were trained in InTouch by experts working, among other things, with physical touch. The training should be held by at least 2 trainers, be a combination of theory and hand-on training, and allow enough time for practicing and questions. Also, subsequent meetings to discuss experiences were considered.

\section{Part 2: Exploratory Qualitative Pilot Study}

A qualitative study design was chosen because qualitative research methods best examine subjective and individual experiences and perceptions; qualitative designs are also useful to generate further hypotheses to be tested in subsequent trials. For this purpose, semi-structured interviews were conducted with nurses ( $n=$ $3)$ applying InTouch and their patients $(n=5)$ with chronic pain 


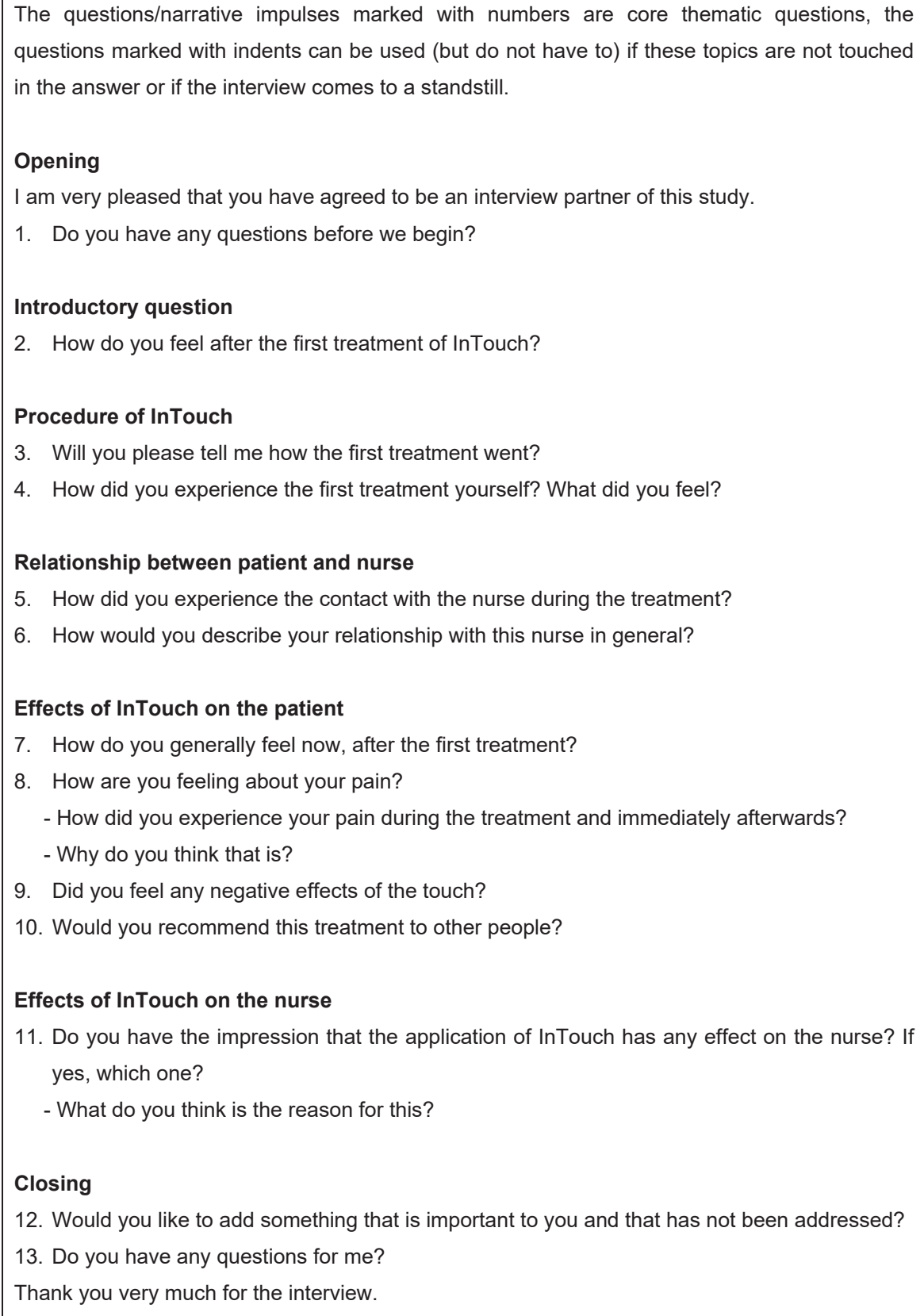

Fig. 1. InTouch interview guide for interview with the patient; assessment point 1.

receiving the intervention. The interviews were conducted by B.S., who is an experienced qualitative researcher. According to the research questions, the interview guide was developed by the research team including the following topics (Fig. 1):

- procedure and perception of InTouch

- relationship to nurse/patient

- perceived effects of InTouch

Inclusion criteria for nurses were being a registered nurse, being trained in InTouch, and providing informed consent. The inclusion criteria stipulated that patients be 65 years old or older, suffer from chronic pain (3-8 on a numeric rating scale of $0-10$ ), be in elderly care (stationary or ambulatory), and provide informed consent. The exclusion criterion for nurses was not being fluent in German. Patients who were unable to consent, had an acute or chronic impairment (beside chronic pain) that disallowed participation, had diagnosed hyper- or dysalgesia, used opioid medication, or were not fluent in German were excluded.

Two assessment points were defined: the first was directly after the beginning of the intervention (week 1) and the second was 4 weeks later. The interviews were complemented by participant observations recorded on video. All interviews were digitally recorded, pseudonymized, transcribed, and deductively and inductively analyzed based on directed Qualitative Content Analysis [12] with the computer program MAXQDA ${ }^{\circledR}$. Categories and codes were developed inductively from the data and deductively from the themes of the structured interview guide and from new topics which arose during research. The video recordings were analyzed based on Qualitative Visual Analysis [13, 14]. Interviews, video recording, coding, and first analyses were conducted by the first author, an experienced qualitative researcher. 
The analytic process was circular, meaning that new insights from the first data analysis were included in the subsequent data gathering and interpretation processes. To improve quality and validity of the analysis and to ensure intersubjectivity, all data were discussed by the research team in regular meetings. The research team consisted of 3 physicians ( 2 were experienced qualitative researchers and 1 also an expert in therapies using physical touch) and 1 study nurse. Furthermore, the analysis was discussed, reflected upon, and optimized in the interdisciplinary qualitative working group at the Charité (Institute of Social Medicine and Institute of Public Health).

\section{Results}

The study was conducted between May 2015 and June 2016. The intervention took place in a nursing home for the elderly in the center of Berlin between July 2015 and January 2016.

\section{Part 1: Development of the Study Intervention on InTouch in Geriatric Care}

In total, 18 persons participated in the stakeholder involvement meeting. These included nurses, experts of therapies using physical touch, patients with chronic pain, and staff of the Institute of Social Medicine of the Charité and the Centre for Quality in Care (ZQP) in Berlin. At this meeting, participants discussed their experiences with physical touch interventions, the issues and effects of intention, and intervention integration into routine nursing care. All participants agreed on the possible trust-building effects of physical touch. The idea that physical touch, combined with an intention of awareness and respect, may improve pain and have a calming effect was also discussed. Interventions should meet the individual needs and wishes of the patients.

Following the stakeholder involvement meeting, the specific InTouch intervention (in this study) was defined and developed by the research team: InTouch does not refer to a specific method or healing system. It refers simply to a soft physical touch with a positive intention to ease complaints and enhance well-being taking into account the individual needs of the patient. The concept is purposely kept simple and refers especially to the possible healing capacities of physical touch and positive intention.

The training took place in a 1-day program. Trainers $(n=3)$ were experts in therapies using physical touch, CIM, and qualitative research. Six nurses (rather than the anticipated 3) received training because of the nursing management's keen interest in this subject. Training was both theoretical and hands-on training; furthermore, the study design was introduced. It took place during 1 whole day with enough time to address all questions in detail.
The intervention of InTouch consisted of the following elements:

1. The nurse uses strategies such as breathing exercises or meditation to develop her own calm mental attitude, centeredness, and focus.

2. The nurse and the patient engage in preintervention talk to clarify where and how the patient would like to be touched during the session.

3. During the intervention itself, the whole hands are placed on the requested region of the body with intention (e.g., awareness, presence, respect, and absence of outcome predisposition). The session ends with hand movements over the whole length of the body or body region. The patient is clothed during the intervention.

4. Optionally, nurse and patient engage in a postintervention discussion about patient responses to the intervention, specific aspects of the session, or future appointments.

5. There is adequate postintervention patient rest.

The session was designed to last for about 10-20 min and occurred, ideally, about 3 times a week.

After 2 months, nurses and trainees met to discuss their experiences with InTouch and relate possible problems that arose during the intervention. After 6 months, a final meeting was held, which combined supervision and further practical exercises in physical touch.

\section{Part 2: Exploratory Qualitative Pilot Study \\ Sample}

Six registered nurses and 6 nursing home patients with chronic pain were included in the study. Nurses were selected by the nursing home management based on their interest in CIM therapies and their generally empathetic attitudes towards patients. Patients were selected by the nursing home management and participating nurses according to the inclusion and exclusion criteria. In total, 24 interviews and 4 participatory video-recorded observations were conducted. The interviews took place in the nursing home with an average length of $28 \mathrm{~min}$ (11-52 min). Nurses were 5 females and 1 male; their mean age was $43 \pm 9.3$ years. Four were registered geriatric nurses, 1 a pediatric nurse, and 1 a general nurse. Patients included 1 male and 5 females; their mean age was $79.5 \pm 9.7$ years. Participatory observation with video analysis was conducted in 4 sessions. Due to the premature ending of their treatment alliance, nurse $(\mathrm{N}) 5$ and patient $(\mathrm{P}) 5$ were not observed. N 6 and P 6 were also not observed because of extreme irregularity of the sessions.

The main codes resulting from the analysis were procedure of treatment, expectations, current complaints, experiencing and perceived effects of InTouch, possible effective factors, relationship between nurse and patient, integration of InTouch in everyday nursing life, current life situation, biographical aspects, and statements about 
the study. All main codes included further codes on a second level, some also on a third level. The main findings, further condensed and relating to the research question, will be presented in detail.

\section{Subjective Experience of InTouch}

All participants, nurses and patients alike, described the sessions as pleasant, soothing, and relaxing.

Exchange of Warmth. The development of physical warmth at the touched parts of the body was of special importance during the sessions. It was experienced as pleasant and at the same time as a kind of "exchange and interplay." That "exchange" seemed to be important for all participants, because it was perceived as "giving and taking." The nurses said it felt good to give something positive to the patients in addition to their daily work. The patients explained that they were happy not only to take and to receive but also to be able to give something to the nurses - their "body warmth."

"Yes, I find this soothing. (...) and then it is also so nicely warm inside. (...) It is somehow beautiful. One does not think about anything anymore." (N 5, interview 1)

"My first impression is that resident [patient] 4 reacts very positive [on the sessions]. She says herself that she begins to become calmer. (...) I personally experienced it as a circulation all in all, because (...) I myself get calmer (...) and it is really as if a kind of energy flow would occur in that exchange of warmth between these two bodies. You can feel the hands get extremely warm, very intense, as if a kind of power circulation happens. You can really feel (...) that giving and taking." ( $\mathrm{N} 4$, interview 1$)$

Relaxation. The nurses reported that the patients in some cases fell asleep during the sessions, which for them indicated relaxation. For the nurses, a crucial factor was "to come down" from their everyday, hectic nursing lives. Yet, sometimes, they had to overcome their everyday attitudes in order to engage with InTouch. Nurses' engagement included becoming more aware of and present to "self" (e.g., to feel exhaustion). Thus, InTouch was said to open nurses to new perspectives: relaxation, quiet, presence, and more subtle perception.

"The session (...) after my early shift (...) yesterday (...) was more exhausting. I was really tired. I would have wanted to just fall asleep, I just could have laid my head on the bed; but it was still pleasant to come down after my duties." (N 1, interview 1)

"At the beginning, Intentional Touch was an effort. Because often you have to work quickly just because of time management. But then to take your time consciously for something and to be aware about you getting in contact with the resident [patient] was strange and needed (...) getting used to in the beginning, but slowly you got into it." ( $\mathrm{N} 5$, interview 1 )

Often, patients rested for an additional time (e.g., another half an hour or one hour) after the session. All participants agreed that the relaxed state continued for the remainder of the day after the session and sometimes into the following day. If the session took place in the evening, patients reported a good night's sleep.

Activation and Empowerment. Patients reported that after resting they felt more energy, joy, drive, and selfconfidence. Things they did not dare to do before and therefore put off could now easily be tackled, e.g., writing a letter. Inspired by the sessions, P 4 even started to lay her own hands on herself.

"After the session I usually rest for another hour. Then I could easily get up and felt so happy (...) there was this joy in me. You can do it, I said to myself. You can do it - wonderful if that would always feel like that. Yes. To get back this joy (...). Suddenly the pencil did not fall out of my hands. My thoughts were back. (...) I could write. (...) And that was very difficult before." (P 1 interview 1)

Because they could give something positive directly to the patients, nurses felt empowered and reevaluated their nursing work. Also, the nurses repeatedly reported feelings of motivation and joy after receiving positive feedback from the patients.

"It's not just for them [the patients]. (...) It opens up a beautiful world (...) it opened up a door to be able to reduce stress and you can do something good every day. (...) You give something, you receive something, (...) that is just great." (N 4, interview 2)

"If she [P 2] said I feel good, that was important to me (...) and then I did not think, (...) I have to do that [Intentional Touch]. (...) No! I wanted to do that and I enjoyed it." (N 2, interview 2)

Four nurses reported that InTouch helped them to become more sensitive to their patients and work (e.g., physical touch in general, present patient's condition).

"Sometimes things are missed out, especially this physical touch, to touch intensely and to look and watch and be aware (...) I am more sensitive now. I noticed it becoming stronger." (N 5, interview 1)

"If you are silent and just listen to yourself and to the other, a kind of vibration occurs and that is different with every other person. (...) There are sometimes pulsations or some vibrations. (...) Sometimes colors occur." (N 4, interview 2)

Adverse Effects. Only 1 patient (P 3) reported an adverse effect, claiming that she suffered from breathlessness and anxiety after the first 2 sessions. P 3 suffered from pulmonary cancer and reported that she had endured many difficulties in her life and that her nerves weren't the strongest. The nurse paused the sessions because of insecurity about that incident, but P 3 nevertheless wanted to continue. In subsequent sessions, InTouch was only practiced with the patient in a sitting position and with sustained conversation between $\mathrm{N} 3$ and $\mathrm{P} 3$. The idea behind that was to keep P 3 in the moment and not let her mind drift away. Breathlessness and anxiety reportedly disappeared. 
Table 1. Pain intensity over time on a $\mathrm{VAS}^{\mathrm{a}}$

\begin{tabular}{lll}
\hline Pseudonym & VAS at baseline & VAS at interview 2 \\
\hline P 1 & $5-6$ & 5 \\
P 2 & 5 & 0 (but peaks up to 7) \\
P 3 & 5 & 5 \\
P 4 & $3-4$ & 2 (but peaks up to 8) \\
P 5 & $7-8$ & 5 \\
P 6 & 4 & 0 \\
\hline
\end{tabular}

VAS, visual analogue scale. ${ }^{a}$ Range of the VAS from 0 to 10 : $0=$ no pain; $10=$ unbearable pain.

P 3: "It actually was quite pleasant, but somehow I noticed that it had made me nervous (...) In the first session it was not that strong, but in the second session - N 3 was gone already - I noticed, oh, you better use your oxygen supply." (...)

I: "Do you have any idea, why you got nervous?" (...)

P 3: "I don't have an explanation for that." (...)

I: "(...) For how long did you need the oxygen supply?" (...)

P 3: "I started it and then I fell asleep."

I: "And how did you sleep?"

P 3: "Actually quite good!" (...)

I: "Would you like to try Intentional Touch again?"

P 3: "Of course." (P 3, interview 1)

\section{Effects of InTouch on Chronic Pain: Subjective}

Perceptions

During the interventions, no patient reported pain. Patients explained that during the sessions their attention was focused on the pleasant sensations of touch and not on pain. That was also the case during the rest period after the session.

"Then [during the session] I do not have any [pain]! (...) Sometimes you just do not think about it.” (P 5, interview 2)

The pain perception after the sessions was described differently by the patients: $\mathrm{P} 1$ reported a distinct pain reduction and used less of her PRN pain medication after receiving InTouch. $P 4$ described a moderate pain reduction, and $\mathrm{P} 2$ reported that due to InTouch she had learned to let her pain "drain":

"In physiotherapy sometimes the pain is building up and I can really notice that when I think about the session I got and which did me good (...) then I notice how it [the pain] flows out of me. (...) I can think it away." (P 2, interview 2)

P 3 and P 5 did not really observe any changes. P 3 was convinced that a period of 1 month was too short to achieve long-lasting effects.

"You know, (...) it was too short. (...) As I said before, when you are really in pain then the treatment should be on a long run." (P 3, interview 2)
Estimation of pain intensity on a visual analogue scale evaluated at baseline and again at the second interview suggested a pain reduction in 4 patients (Table 1). Yet, patients reported difficulties in giving an average estimation on the scale, which might be an explanation why the estimation on the visual analogue scale does not always correspond to the interviews (e.g., P 5).

\section{Therapeutic Relationship}

At the beginning of the study, all participants agreed that establishing rapport was a critical trust-building element for InTouch. While the nurse-patient relationship did not need to be very profound (indeed, some of the nurses worked on different wards than their InTouch patients and barely knew them), a positive attitude was deemed essential to ensure the success of such an intimate treatment. Additionally, honest communication about such things as personality differences or discomfort during the session was an essential component of trust building, without which a treatment should ideally not even be commenced. Yet, this was not always easy. For example, $\mathrm{P} 2$ did not feel any particular dislike for $\mathrm{N} 2$, yet the patient felt emotional distance from $\mathrm{N} 2$ from the beginning of the intervention; she felt unable to express her concerns because she felt insecure and did not wish to hurt $\mathrm{N}$ 2's feelings.

"I felt a bit insecure with this laying on of hands, because I have the feeling that she [N 2] does not really understand what I want to say. (...) she just feels distant to me." (P 2, interview 2)

"It is about the chemistry, if the chemistry is right. With some residents [patients] I wouldn't do Intentional Touch in specific regions of the body. (...) Indeed, there are residents [patients] I cannot imagine doing it at all." (N 4, interview 2)

Over time, participants reported that increased familiarity with each other enhanced communication and trust. Patients reported gratitude for the time and attention they received from nurses and looked forward to more sessions. Reliability was another factor affecting the therapeutic relationship, underscored by the interaction between $\mathrm{N} 5$ und $\mathrm{P} 5$. In the beginning, $\mathrm{P} 5$ and $\mathrm{N} 5$ liked each other. However, when $\mathrm{N} 5$ repeatedly altered the appointment schedule - sometimes without even calling - $\mathrm{P}$ 5 became disappointed, lost trust in N 5, and terminated further treatments. Thereafter, P 5 herself arranged for treatments with $\mathrm{N} 3$, whom she liked and deemed to be more reliable.

"No, (...) she [N 5] would never have come back anyway, she just left me totally alone and it would never have become better again. Once and never again." (P 5, interview 2)

During participatory observation, all nurses and patients seemed to work together well with mutual understanding and minimal clarification requirements. For 3 
nurse-patient pairs, contact was very trusting and joyful. P 3 revealed her personal concerns (e.g., death, age) and seemed to enjoy the fact that N 3 listened. She also reported to $\mathrm{N} 3$ positive feelings about physical touch to her shoulder and arm. Only within the N 2-P 2 dynamic, a degree of tension and insecurity could be felt by the observer, which was possibly enforced by the video recording situation.

Intervention Organization and Procedure

Participants reported that the interventions took place after individual arrangements between nurse and patients had been made. Interventions lasted up to half an hour. Most nurses reported that they entered the session with an intention/inner attitude of "open curiosity" about the session. Nurses reported that they concentrated on their breathing in the sessions, which helped to maintain focus. In the opening conversation, all patients said that they wanted to be touched at, or close to, their respective pain loci. In general, silence was maintained to foster calmness and relaxation, although 2 patients preferred conversation and exchange with the nurse during the session.

"They [the patients] register that they are not alone, that one takes time for them, to be there, present, just like that. And they enjoy the calmness and the silence just not to say anything." (N 5, interview 2)

"I am always happy, when N 3 comes again (laughing). (...) it is very comfortable with her and she is just a great conversational partner." (P 5, interview 2)

Nurses reported difficulty organizing 2-3 regular treatment sessions per week due to shift work, time off, holidays, and absences of team members due to illness. To foster continuity, nurses established a system of alternate nurses, which was said to have been broadly accepted by the patients if a rapport between alternate nurse and patient existed.

Within the participatory observation, 3 video-recorded sessions captured patients in sitting positions; 1 recording captured a patient in a supine position. Three sessions took place mostly in silence; the observer sensed the increasing relaxation and quiet. All participants appeared to sink into an attentive, almost reverent state. The nurses appeared to be present and focused. This atmosphere took several minutes to be established; in the beginning, the observer had the impression that everyone first had to let him-/herself get involved in the situation. The sessions ended also mostly in silence or with a short goodbye without conversations. Two patients fell asleep during their sessions, and 2 patients were encouraged by the nurses to rest a bit longer.

\section{Integration in Everyday Nursing Life}

Half of the nurses reported that they performed InTouch only when they were off duty. Especially for registered nurses, there would be so much to do during a shift. Often, a nurse would be alone on or responsible for a whole ward. Therefore, they just would not have the time and could not give their attention to the sessions.

"You absolutely don't have the tranquility to really relax, because a qualified nurse is always in demand. (...) And to ask a colleague to take over can work out or not. Better doing it [Intentional Touch] before or after the shift and then you are really relaxed. Without being rushed (...) In your shift that is pure hectic." ( $\mathrm{N} 1$, interview 1)

The other half of the nurses reported being able to integrate the sessions into their shifts. That integration required an extremely disciplined workload structure, understanding colleagues, and no unforeseen occurrences. Furthermore, fixed appointments could be difficult to attain during the shifts. $\mathrm{N} 5$ said she was able to weave short sequences of InTouch in her general nursing care to avoid appointments.

"I did it during my shifts (...) As long as there is no real emergency case I do it like that. I informed my colleagues and that I will be away for half an hour and that I also would be out of reach by telephone. (...) When I come back I would do the rest [of my work]." (N 4, interview 1$)$

"I do it in my nursing care, I integrate it. In the sense that I am not making appointments or announcements because I cannot really keep it. But it [Intentional Touch] is now a fixed part in (...) my nursing sequences (...) I just sit at the bedside (...) and consciously take time for that." (N 5, interview 2)

\section{Discussion}

Nurses and patients equally described relaxation, wellbeing, and a sensation of warmth during the intervention, and patients felt no pain. Over time, 3 patients experienced pain relief and 3 perceived no change in pain beyond the treatment. Furthermore, patients described better drive and positive feelings after the treatment. Nurses felt more empowered and reported a reevaluation of their nursing work. Empathetic attention, continuity, and reliability were important for a trustful therapeutic relationship.

\section{Strengths and Limitations}

One strength of the study was the integration of stakeholder input into the development of the concept: the practicality and implementability of integrating the intervention into everyday nursing work was taken into account. In addition, training was conducted by 3 experts with different qualifications (physical touch skills, teaching skills in CIM, and scientific skills). Furthermore, re- 
peated supervision and additional trainings were given throughout the duration of the study. Another strength of the study was the elaborated qualitative study design of interviews, which included the treatment process, and the additional participatory observation with video recording and analysis.

One limitation could be that the first author was part of the development of the intervention and the training. She also conducted the data collection and coding. Therefore, possible subjective influences on the results have to be considered. Still, this possible source of bias was addressed by regular discussions during the whole study process by the research team. Furthermore, the data analysis was discussed and reflected upon by the interdisciplinary qualitative working group at the Charité. Selection bias of the participating nurses has to be considered because the selection was undertaken by the nursing management. It is possible that especially open, engaged, and empathetic nurses were selected. Yet, these characteristics already underline the prerequisites for nurses who provide InTouch.

\section{Perceived Effects of InTouch}

Nurses and patients described relaxation, well-being, and warmth equally for the treated and the treating person as key results of InTouch. These outcomes are consistent with results of other studies about therapeutic touch [5-7]. These positive effects carried various implications beyond the treatment sessions themselves: patients described better drive, positive feelings (e.g., joy), and improved self-confidence, which suggest improved self-efficacy. These findings may be understood as consequences of the relaxation induced by the intervention [15].

The reports of the nurses can also be understood in terms of empowerment and nurses' inclinations to reevaluate their nursing work. Through positive patient feedback and their own positive experiences, health promotion and salutogenetic values were recalled (e.g., to support health, healing, well-being, and self-care) which were once important to their career choices [9].

According to the patients, InTouch had a direct effect: pain amelioration. This effect fits with results of other studies on therapeutic touch $[4,5,7,16]$. Patients felt no pain during their treatments. Beyond the treatment, 3 patients experienced pain relief and 3 patients experienced no change in pain perception. The processing of physical touch contains sensory, affective, and cognitive components $[17,18]$. Cognitive aspects could play a role in the sense of reframing the pain (e.g., not regarding the pain as as important as before because patients also experienced other qualities when the painful areas were touched: well-being, human warmth, and relaxation). Obviously, some patients learned creatively and inde- pendently (e.g., to "think the pain away"), as P 2 did. With P 3, the influence of expectations is remarkable: she expected that her chronic pain, which may have already existed for years, could not be improved by only 1 month's treatment.

\section{Interplay, Empathy, and Being Taken Seriously}

Empathetic attention expressed through physical touch had special importance for the relationship between nurses and patients. Patients witnessed nurses who took time for them and let themselves get involved, which is unusual in a nursing home for the elderly. The aspect of being taken seriously seemed to play an important role. Patients' complaints, here in the form of pain, were taken seriously, demonstrated by the attention to the wish for the physical touch at or close to the pain loci in the treatment sessions. Furthermore, the whole person was taken seriously; the patients were the ones who decided where and how the physical touch should occur. In the conversations during the treatment sessions, nurses listened to patients' thoughts and sorrows. Also, the nurses learned through InTouch to take themselves seriously; their perceptions were equally seen as important and even required, because only then a positive effect for the patient and oneself was possible. The interplay between nurses and patients was also striking for all participants in the nonverbal exchange of human warmth, relaxation, and joy. Morrison et al. [19] described the skin as a social organ: beyond physical sensations, social information (e.g., emotions) is passed on through physical touch. According to our study results, a correlation exists between physical warmth and emotional warmth.

\section{Inner Attitude and Intention}

The nurses also saw the inner attitude/intention they developed during treatment sessions as important (e.g., open curiosity, mindful perception, and focus). It was important for them to enter a session without expectation (e.g., pain reduction). Such an intention might raise pressure to achieve a specific outcome.

Nurses reported some difficulty developing an inner attitude that allowed them to achieve mindfulness, nonjudgment, and awareness of the moment (presence), away from the hectic atmosphere of their everyday work life. Furthermore, achieving this state involved aspects of endurance: of quietness and silence, of focus on the other and on oneself, including perceptions of the various manifestations that result from increased focus (e.g., the breathlessness of P 3, or nurse's exhaustion). InTouch seems able to raise emotions, memories, and aspects of the personality which might have been pushed to the back of one's mind. However, once InTouch has been experienced, the resulting relaxation and serenity encourage cognitive, emotional, and physical recovery. Zahourek 
and Larkin [9] emphasize that the intention can influence healing processes (e.g., prayers). But they also admit that the effect of intention is very difficult, if not impossible, to quantify, because intention cannot be measured.

A positive intention can also be related to the concept of compassion. Compassion implies adding a positive feeling or intention for the other to empathetic understanding. By allowing these positive feelings and intentions for the other to surface, the compassionate person is fostering positive feelings for him that may augment the person's resilience and coping in stressful situations [20].

\section{Active Nonverbal Listening}

In communication research, active listening is an important part of empathy [21]. In the InTouch model, we talk about active nonverbal listening: active because it is mindful, open, and intentional, and nonverbal because the focus is not on verbalization, which is always an abstraction of direct experience. Both the applying and receiving person listen through the direct experience of physical touch. Therefore, the communication is not based on an abstract, rationalized verbalization. Rather, InTouch allows an important and high-quality communication between participants that is not necessarily achieved verbally (e.g., deep feeling of relaxation, self-reflection, and trust).

\section{Integration of InTouch into Everyday Nursing Work}

The integration into everyday nursing work was a challenge. Although all nurses were highly motivated during the study, it became obvious that reliable and continuous treatments were difficult to organize due to a lack of time and irregular work shifts. Yet, reliability and continuity seemed to be essential to establish a trusting relationship between receiver and applier. Similarly, reliability and continuity may play a role in the potential lasting effectiveness of InTouch. One possibility seems to be the integration of short treatment sequences into daily nursing activities (e.g., washing, bedding). Yet, such procedures would have to be observed carefully. In short sequences, especially if the nurse is not experienced in InTouch, the treatment may become unfocused, and the nurse's engagement and awareness might not be optimal.

Another challenge is the open and honest communication that allows for the possibility that a treatment from or for a person may be rejected. However, the current medical system and the generation of elderly people are generally paternally oriented (i.e., they see the world as hierarchically structured) and are less well acquainted with collaborative partnerships [22]. Assuming a hierarchical structure, it could be difficult for both nurses and patients to refuse a proposed treatment or to speak up during a session if something was unpleasant. In the training and supervi- sion of nurses, this assumption would have to be addressed regularly, so that nurses become empowered to communicate honestly with themselves and with their patients.

\section{Possible Outcomes for Quantitative Studies}

The qualitative study design allowed for an improved understanding of various subjective experiences with and perceptions of InTouch. Summing up the results of our study, possible outcomes for subsequent quantitative studies could be measures of well-being, quality of life, intensity of complaints, stress, therapeutic relationship, self-efficacy, work satisfaction, introspection, and expectation. It would make sense to combine these aspects with the measurement of physiological parameters for relaxation responses (e.g., oxytocin and cortisol level as objective measurements for stress).

\section{Conclusions}

The results of this study suggest that InTouch is a therapeutic tool that may promote relaxation, well-being, and pain relief in elderly people suffering from chronic pain and that it enhances the therapeutic relationship. Positive influences are empathetic attention, the feeling of being taken seriously, and the exchange of human warmth through physical touch. Furthermore, InTouch can enhance mindful and nonjudgmental awareness of the other and oneself, drive, self-confidence, self-efficacy, and empowerment and can prompt a reevaluation of nursing work. These hypotheses should be tested for further medical indications and in future quantitative studies.

Advanced awareness of the other and oneself can be challenging if unpleasant feelings occur. The establishment of good rapport, empathetic attention, honest communication, and the willingness to allow intimacy seems to be a prerequisite for InTouch. Furthermore, strategies for the implementation into everyday nursing work seem to be of central importance.

\section{Acknowledgements}

The authors thank all the participants of the study and the study nurse Margit Cree. They also thank Felix Falkenhahn and Annette Kerckhoff, who conducted the training for InTouch with B.S. Felix Falkenhahn also conducted the supervision meetings of the nurses with B.S. Furthermore, we thank Shelly Rafferty Withers, PhD, of Journal Ready USA, Troy, NY, USA, for editing the paper.

\section{Statement of Ethics}

Participants provided written informed consent. The study was approved by the ethics committee of Charité Universitätsmedizin Berlin (EA1/112/15). 


\section{Disclosure Statement}

The authors declare that they have no competing interests.

\section{Funding Sources}

The work was supported by the Centre for Quality in Care (ZQP), Berlin, Germany.

\section{References}

1 Cocksedge S, George B, Renwick S, ChewGraham CA. Touch in primary care consultations: qualitative investigation of doctors' and patients' perceptions. Br J Gen Pract. 2013 Apr;63(609):e283-90.

2 Bruhn JG. The doctor's touch: tactile communication in the doctor-patient relationship. South Med J. 1978 Dec;71(12):1469-73.

3 Stöckigt B, Teut M, Witt CM. CAM Use and Suggestions for Medical Care of Senior Citizens: A Qualitative Study Using the World Café Method. Evid Based Complement Alternat Med. 2013;2013:951245.

4 Anderson JG, Suchicital L, Lang M, Kukic A, Mangione L, Swengros D, et al. The effects of healing touch on pain, nausea, and anxiety following bariatric surgery: a pilot study. Explore (NY). 2015 May-Jun;11(3):208-16.

5 Anderson JG, Taylor AG. Effects of healing touch in clinical practice: a systematic review of randomized clinical trials. J Holist Nurs. 2011 Sep;29(3):221-8.

6 Bush E. The use of human touch to improve the well-being of older adults. A holistic nursing intervention. J Holist Nurs. 2001 Sep; 19(3):256-70.
7 Monroe CM. The effects of therapeutic touch on pain. J Holist Nurs. 2009 Jun;27(2):85-92.

8 Stone J. Transforming the patient experience through presence and intention. Beginnings. 2014;34:12-13, 16-17.

9 Zahourek RP, Larkin DM. Consciousness, intentionality, and community: unitary perspectives and research. Nurs Sci Q. 2009 Jan; 22(1):15-22.

10 Gagliese L. Pain and aging: the emergence of a new subfield of pain research. J Pain. 2009 Apr;10(4):343-53.

11 Molton IR, Terrill AL. Overview of persistent pain in older adults. Am Psychol. 2014 FebMar;69(2):197-207.

12 Hsieh HF, Shannon SE. Three approaches to qualitative content analysis. Qual Health Res. 2005 Nov;15(9):1277-88.

13 Bohnsack R. Qualitative Bild- und Videointerpretation: Die dokumentarische Methode. 2nd ed. Opladen, Farmington Hills: Verlag Barbara Budrich; 2011.

14 Denzin NK. Reading Film - Filme und Videos als sozialwissenschaftliches Erfahrungsmaterial. In: Flick U, von Kardorff E, Steinke I, editors. Qualitative Forschung: Ein Handbuch. 4th ed. Hamburg: Rowohlt; 2005. pp. 416-428
15 Esch T, Stefano GB. The neurobiology of stress management. Neuro Endocrinol Lett. 2010;31(1):19-39.

16 Jain S, Mills PJ. Biofield therapies: helpful or full of hype? A best evidence synthesis. Int J Behav Med. 2010 Mar;17(1):1-16.

17 Lucas MV, Anderson LC, Bolling DZ, Pelphrey KA, Kaiser MD. Dissociating the Neural Correlates of Experiencing and Imagining Affective Touch. Cereb Cortex. 2015 Sep; 25(9):2623-30.

18 McGlone F, Vallbo AB, Olausson H, Loken L, Wessberg J. Discriminative touch and emotional touch. Can J Exp Psychol. 2007 Sep; 61(3):173-83.

19 Morrison I, Löken LS, Olausson H. The skin as a social organ. Exp Brain Res. 2010 Jul; 204(3):305-14.

20 Singer T, Klimecki OM. Empathy and compassion. Curr Biol. 2014 Sep;24(18):R875-8.

21 Hashim MJ. Patient-Centered Communication: basic Skills. Am Fam Physician. 2017 Jan;95(1):29-34.

22 Coulter A. Paternalism or partnership? Patients have grown up-and there's no going back. BMJ. 1999 Sep;319(7212):719-20. 